\title{
Echocardiographic assessment of left ventricular function in coronary arterial disease
}

\author{
P. A. N. CHANDRARATNA, A. RASHID, A. TOLENTINO, F. J. HILDNER \\ A. FESTER, P. SAMET, B. B. LITTMAN, AND S. SABHARWAL \\ With the technical assistance of $D$. Gindlesperger \\ From the Division of Cardiology, Department of Medicine, Mount Sinai Medical Center, \\ Miami Beach, Florida, and the University of Miami School of Medicine, Coral Gables, U.S.A.
}

This investigation was designed to determine the role of echocardiography in the assessment of left ventricular function in patients with significant coronary arterial disease. Satisfactory echocardiograms were obtained in 43 patients with coronary arterial disease. The ventriculographic ejection fraction was determined by the area length method. The echocardiographic left ventricular end-diastolic dimension was increased to more than $5.4 \mathrm{~cm}$ in 17 patients. Fifteen of these patients had an ejection fraction of 0.45 or less. Three patients had a normal left ventricular end-diastolic dimension but an ejection fraction of less than 0.45. Twenty-three patients had an ejection fraction of more than 0.45 and a normal left ventricular end-diastolic dimension. The left ventricular end-diastolic dimension index was increased $\left(>3 \mathrm{~cm} / \mathrm{m}^{2}\right)$ in 15 patients, all of whom had ejection fraction of less than 0.45. Three patients had a normal left ventricular end-diastolic dimension index and an ejection fraction of less than 0.45. Twenty-five patients had a left ventricular enddiastolic dimension index of less than $3 \mathrm{~cm} / \mathrm{m}^{2}$ or less and an ejection fraction of more than 0.45 . The percentage fractional shortening of the echocardiographic left ventricular dimension was reduced in 25 patients. In 18 of these the ejection fraction was 0.45 or less. The percentage fractional shortening of the left ventricle was normal in 18 patients. In 2 of them the ejection fraction was less than 0.45 . In summary, increase of the left ventricular end-diastolic dimension or left ventricular end-diastolic dimension index is usually associated with a critical reduction of the ejection fraction as determined by ventriculography. Since the ejection fraction is an important determinant of mortality related to bypass graft surgery, echocardiography should be useful in the detection of patients with a poor prognosis.

Echocardiography has proved to be a valuable noninvasive tool in the assessment of patients with valvular heart disease and congenital anomalies of the heart (Zaky et al., 1968; Feigenbaum, 1972; Chung et al., 1973; Popp et al., 1974). The usefulness of this technique in the evaluation of left ventricular function has been established (McDonald et al., 1972; McDonald and Hobson, 1974; Quinones et al., 1974). Recent studies have shown that echocardiography may be used to detect abnormalities of left ventricular wall motion, in patients with coronary arterial disease (Jacobs et al., 1973; Corya et al., 1974a).

Aortocoronary saphenous vein graft surgery has been shown to produce symptomatic improvement in the majority of patients with angina pectoris (Spencer, 1970). The mortality associated with this operation is considerably higher in those patients Received for publication 18 August 1976 who have poor left ventricular function (Committee on Coronary Artery Surgery, 1972; Cohn et al., 1974). Thus, the ability to predict poor left ventricular function in such patients by a noninvasive method would be of considerable value. This investigation was designed to determine whether an increase in the echocardiographic left ventricular dimension reflects a critical reduction of the ejection fraction.

\section{Methods}

Echocardiography was performed on 43 patients who underwent cardiac catheterisation for symptomatic coronary arterial disease. Patients with mitral regurgitation were excluded from the study. One of the patients was in congestive cardiac failure and all the patients were in sinus rhythm at the time of the study. Significant stenosis $(>75 \%)$ of one or more 
coronary arteries was detected by coronary arteriography in 37 patients. Six patients did not have coronary angiography (because severe left ventricular dysfunction was present on the left ventriculogram) but had a past history of a well-documented myocardial infarction. The patients were examined in the supine position. The echocardiograms were performed within 24 hours of the catheterisation studies. A $2.25 \mathrm{MHz}, 1.27 \mathrm{~cm}, 10 \mathrm{~cm}$ focus transducer, an Ekoline 20 ultrasonoscope, and an Electronics for Medicine DR8 recorder were used. The only criterion for patient selection was a technically adequate recording, on which left ventricular echoes could be clearly identified. Satisfactory tracings were obtained in 71 per cent of all patients studied; thus, the 43 subjects of the study were selected from a group of 60 consecutive patients. Left ventricular cineangiocardiography was performed in the right anterior oblique projection. The left ventricular volume and the ejection fraction were calculated using the area-length method (Sandler and Dodge, 1968).

The echocardiographic measurements of the left ventricular dimensions were made at a level just caudal to the mitral valve. The left ventricular enddiastolic dimension (LVED) was measured at the apex of the $R$ wave of the electrocardiogram. The left ventricular end-systolic dimension (LVES) was measured as the shortest recorded distance between the left ventricular septal and posterior wall endocardial echo. The thicknesses of the septum and of the left ventricular posterior wall were measured as previously described by Corya et al., $1974 \mathrm{~b}$. The percentage fractional shortening of the left ventricular dimension ( $\%$ FSLV) was calculated as follows:

$$
\frac{(\text { LVED-LVES) }}{\text { LVED }} \times 100 \text {. }
$$

The echocardiographic measurements were made by averaging five consecutive beats in which the endocardial echoes from the septum and posterior wall were clearly seen. The various measurements were made by two observers. The beat-to-beat variation was $2 \mathrm{~mm}$ or less. The interobserver variation was also $2 \mathrm{~mm}$ or less.

\section{Results}

The results are given in the Table. There were 34 men and 9 women. Their ages ranged from 35 to 66 years. Fig. 1 shows the relation between the ventriculographic ejection fraction and the left ventricular end diastolic dimension (LVED) determined by echocardiography. An ejection fraction of 0.45 or less was taken as evidence of significant left ventricular dysfunction (Committee on Coronary Artery Surgery, 1972).

Values obtained in our laboratory from 32 normal subjects ( 25 men and 7 women) have been used as normal for the purpose of this paper.

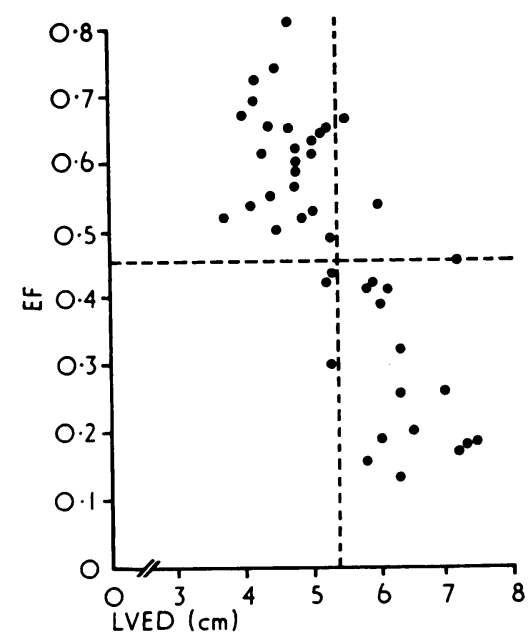

Fig. 1 The relation between the echocardiographic left ventricular end-diastolic dimension (LVED) in $\mathrm{cm}$ and the ventriculographically determined ejection fraction $(E F)$. The vertical dotted line indicates the upper limit of normal (5.4) for the LVED. The horizontal dotted line corresponds to an ejection fraction of $0 \cdot 45$. The correlation coefficient is -0.78 .

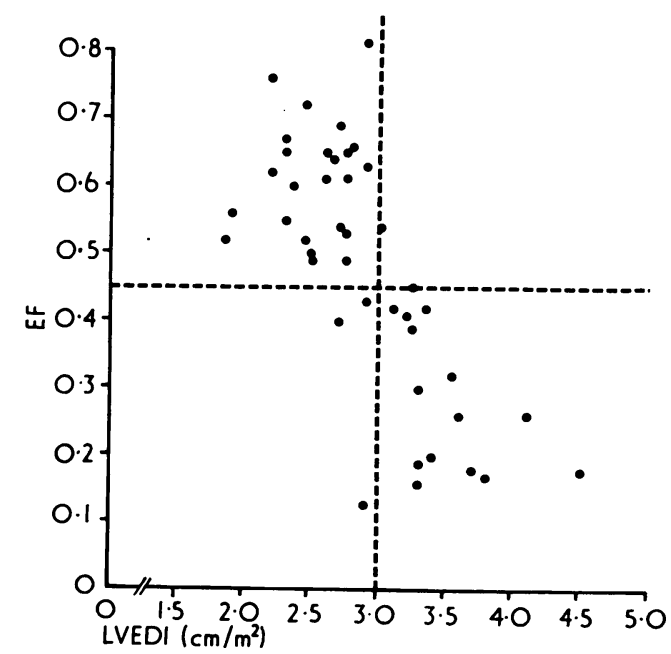

Fig. 2 The relation between the left ventricular enddiastolic dimension index (LVEDI) in $\mathrm{cm} / \mathrm{m}^{2}$ and the ejection fraction. The vertical dotted line corresponds to the upper limit of normal $\left(3 \mathrm{~cm} / \mathrm{m}^{2}\right)$ for the LVEDI. The correlation coefficient is -0.73 . 
Table

\begin{tabular}{|c|c|c|c|c|c|c|c|c|c|c|}
\hline $\begin{array}{l}\text { Case } \\
\text { no. }\end{array}$ & Age & Sex & $E F$ & $L V E D V I$ & LVED & $L V E D I$ & $L V P W E$ & $I V S E$ & $\% F S L V$ & $C A D$ \\
\hline 1 & 51 & $\mathbf{M}$ & 0.56 & 46 & $4 \cdot 8$ & 1.85 & $1 \cdot 1$ & $0 \cdot 7$ & 32 & RCA, LAD, CCA, Marg \\
\hline 2 & 64 & $\mathbf{M}$ & 0.18 & 116 & $7 \cdot 4$ & $3 \cdot 7$ & 0.2 & $1 \cdot 2$ & 19 & LAD, CCA, RCA \\
\hline 3 & 50 & M & 0.53 & 84 & $5 \cdot 0$ & $2 \cdot 75$ & $1 \cdot 3$ & $1 \cdot 0$ & 46 & LAD, RCA \\
\hline 4 & 58 & $\mathbf{M}$ & 0.32 & 96 & $6 \cdot 3$ & $3 \cdot 56$ & $1 \cdot 7$ & 0 & 21 & LAD, Marg \\
\hline 5 & 52 & $\mathrm{M}$ & 0.41 & 126 & 6.0 & $3 \cdot 2$ & $0 \cdot 7$ & $\mathbf{P}$ & 12 & CCA, RCA, LAD \\
\hline 6 & 44 & M & 0.26 & 132 & $6 \cdot 3$ & $3 \cdot 6$ & $1 \cdot 0$ & 0 & 25 & LAD, RCA \\
\hline 7 & 43 & $\mathrm{M}$ & 0.64 & 65 & $5 \cdot 1$ & $2 \cdot 66$ & $1 \cdot 3$ & $1 \cdot 0$ & 39 & CCA, RCA, LAD \\
\hline 8 & 44 & $M$ & 0.61 & 83 & $5 \cdot 0$ & $2 \cdot 75$ & $1 \cdot 3$ & $1 \cdot 2$ & 44 & CCA, RCA, LAD \\
\hline 9 & 61 & $\mathbf{F}$ & 0.61 & 54 & $4 \cdot 3$ & $2 \cdot 6$ & $1 \cdot 6$ & 0.8 & 51 & CCA, RCA, LAD \\
\hline 10 & 48 & $\mathbf{M}$ & 0.43 & 90 & $5 \cdot 3$ & $2 \cdot 9$ & $0 \cdot 3$ & $0 \cdot 7$ & 17 & RCA, LAD \\
\hline 11 & 35 & $\mathbf{M}$ & 0.5 & 67 & $4 \cdot 5$ & $2 \cdot 5$ & $0 \cdot 8$ & $0 \cdot 7$ & 33 & RCA, LAD, Marg \\
\hline 12 & 60 & $M$ & 0.42 & 73 & $5 \cdot 9$ & $3 \cdot 35$ & 1.9 & 0 & 32 & CCA, LAD, RCA \\
\hline 13 & 47 & $\mathbf{F}$ & 0.63 & 61 & $5 \cdot 0$ & $2 \cdot 9$ & $1 \cdot 3$ & 0 & 14 & LAD, Diag \\
\hline 14 & 56 & $\mathrm{M}$ & 0.54 & 87 & $6 \cdot 0$ & $3 \cdot 0$ & 0.8 & 0.9 & 28 & CCA, RCA \\
\hline 15 & 57 & $M$ & 0.65 & 116 & $4 \cdot 7$ & $2 \cdot 6$ & $1 \cdot 1$ & 0 & 23 & CCA, RCA, LAD \\
\hline 16 & 38 & $\mathbf{M}$ & 0.65 & 89 & $5 \cdot 2$ & $2 \cdot 75$ & $1 \cdot 0$ & $1 \cdot 2$ & 40 & RCA, LAD \\
\hline 17 & 54 & $\mathbf{F}$ & 0.54 & 93 & $4 \cdot 1$ & $2 \cdot 7$ & $1 \cdot 1$ & $0 . \overline{4}$ & 37 & RCA, LAD \\
\hline 18 & 56 & $\mathbf{M}$ & 0.39 & 96 & $6 \cdot 0$ & $3 \cdot 24$ & 0.3 & 0.9 & 20 & - \\
\hline 19 & 53 & $M$ & 0.67 & 76 & $4 \cdot 0$ & $2 \cdot 3$ & $1 \cdot 2$ & 0.4 & 40 & CCA, RCA, LAD \\
\hline 20 & 61 & $M$ & 0.19 & 114 & $6 \cdot 0$ & $3 \cdot 3$ & 0.3 & 0.8 & 16 & - \\
\hline 21 & 40 & $\mathbf{M}$ & $0 \cdot 17$ & 155 & $7 \cdot 3$ & $3 \cdot 8$ & $1 \cdot 7$ & 0 & 19 & 一 \\
\hline 22 & 57 & $M$ & 0.6 & 59 & $4 \cdot 8$ & $2 \cdot 35$ & $1 \cdot 0$ & 0.3 & 27 & RCA, LAD, Marg \\
\hline 23 & 60 & $M$ & 0.49 & 55 & $5 \cdot 3$ & $2 \cdot 76$ & $1 \cdot 4$ & 0.9 & 44 & CCA, RCA, LAD \\
\hline 24 & 58 & $M$ & 0.52 & 71 & $3 \cdot 7$ & $1 \cdot 85$ & $1 \cdot 7$ & 0 & 38 & LAD \\
\hline 25 & 52 & $\mathbf{F}$ & 0.69 & 63 & $4 \cdot 2$ & $2 \cdot 7$ & $1 \cdot 7$ & 0.6 & 45 & LAD, Diag \\
\hline 26 & 66 & $\mathbf{F}$ & 0.82 & 56 & $4 \cdot 7$ & $2 \cdot 9$ & $1 \cdot 2$ & 0.9 & 38 & CCA, RCA, LAD \\
\hline 27 & 64 & M & 0.2 & 161 & $6 \cdot 5$ & $3 \cdot 4$ & 1.0 & 0.8 & 15 & CCA, RCA, LAD \\
\hline 28 & 47 & M & 0.55 & 51 & $4 \cdot 4$ & $2 \cdot 3$ & 0.8 & 0.5 & 27 & RCA, LAD, Marg \\
\hline 29 & 49 & $M$ & 0.65 & 90 & $4 \cdot 4$ & $2 \cdot 3$ & 1.0 & 0.7 & 32 & RCA, LAD, Diag \\
\hline 30 & 63 & $\mathbf{F}$ & 0.3 & 121 & $5 \cdot 3$ & $3 \cdot 3$ & 1.0 & 0.7 & 30 & MLCA, LAD, RCA \\
\hline 31 & 53 & $\mathbf{M}$ & $0 \cdot 13$ & 94 & $6 \cdot 3$ & $2 \cdot 9$ & $1 \cdot 7$ & $\mathbf{0}$ & 28 & LAD, RCA \\
\hline 32 & 44 & $\mathrm{M}$ & 0.66 & 62 & $5 \cdot 5$ & $2 \cdot 8$ & 1.0 & 0.8 & 33 & RCA, LAD, Marg \\
\hline 33 & 62 & $\mathbf{F}$ & 0.42 & 69 & $5 \cdot 2$ & $3 \cdot 1$ & $1 \cdot 3$ & 0.4 & 27 & CCA, RCA, LAD \\
\hline 34 & 46 & $\mathbf{M}$ & 0.40 & 96 & $5 \cdot 8$ & $2 \cdot 7$ & 0.8 & $0 \cdot 8$ & 28 & CCA, LAD \\
\hline 35 & 58 & $M$ & $0 \cdot 16$ & 159 & $5 \cdot 8$ & $3 \cdot 3$ & 0.3 & 0.8 & 16 & \\
\hline 36 & 66 & $M$ & 0.49 & 75 & $5 \cdot 3$ & $2 \cdot 5$ & $1 \cdot 1$ & 0 & 17 & CCA, LAD \\
\hline 37 & 46 & $\mathrm{M}$ & 0.75 & 65 & $4 \cdot 5$ & $2 \cdot 2$ & $1 \cdot 6$ & 0 & 33 & CCA, LAD, RCA \\
\hline 38 & 40 & $M$ & $0 \cdot 26$ & 135 & $7 \cdot 0$ & $4 \cdot 1$ & $0 \cdot 7$ & $1 \cdot 2$ & 26 & — \\
\hline 39 & 46 & M & 0.45 & 140 & $7 \cdot 2$ & $3 \cdot 26$ & 1.5 & 0.4 & 26 & 一 \\
\hline 40 & 61 & $\mathrm{~F}$ & $0 \cdot 18$ & 141 & $7 \cdot 3$ & $4 \cdot 5$ & $1 \cdot 3$ & $\mathbf{0}$ & 15 & LAD, RCA \\
\hline 41 & 57 & $\mathrm{M}$ & 0.52 & 75 & 4.9 & $2 \cdot 45$ & $1 \cdot 0$ & 0.9 & 39 & RCA, LAD, Marg \\
\hline 42 & 58 & $\mathbf{F}$ & 0.72 & 76 & $4 \cdot 2$ & $2 \cdot 45$ & $1 \cdot 1$ & 0.7 & 29 & CCA, RCA, LAD \\
\hline 43 & 39 & $\mathbf{M}$ & 0.62 & 55 & $4 \cdot 8$ & $2 \cdot 2$ & $0 \cdot 7$ & $\mathbf{P}$ & 13 & LAD \\
\hline
\end{tabular}

EF, ventriculographic ejection fraction; LVEDVI, ventriculographic left ventricular end-diastolic volume index in $\mathrm{ml} / \mathrm{m}^{2}$ body surface area; LVED, left ventricular end-diastolic dimension in $\mathrm{cm} ;$ LVEDI, LVED index $\mathrm{cm} / \mathrm{m}^{2}$ body surface area; LVPWE, left ventricular posterior wall excursion in cm; IVSE, excursion of the interventricular septum in $\mathrm{cm} ; \% \mathrm{FSLV}$, percentage fractional shortening of the echocardiographic left ventricular dimension; CAD, coronary artery disease; RCA, right coronary artery; LAD, left anterior descending artery; CCA circumflex coronary artery; Marg, marginal branch of CCA; Diag, diagonal branch of the LAD; MLCA, main left coronary artery; P, paradoxical motion of the septum.

Twenty-five subjects were between the ages of 25 and 35 and the other 7 were between 45 and 50 years. There were no significant differences in the left ventricular values between the two age groups.

The upper limit of normal for the LVED in our laboratory is $5.4 \mathrm{~cm}$. The LVED was increased $(>5.4 \mathrm{~cm})$ in 17 patients. Fifteen of these patients had an ejection fraction (EF) of 0.45 or less. Three patients had a normal LVED but an ejection fraction of $<0.45$. Twenty-three patients had a normal LVED and an EF of $>0.45$. The relation between the ventriculographic ejection fraction and the echocardiographic left ventricular end-diastolic dimension index was also determined (Fig. 2). Fifteen patients had a left ventricular end-diastolic dimension index (LVEDI) of $>3 \mathrm{~cm} / \mathrm{m}^{2}$, all of whom had an ejection fraction of 0.45 or less. (The upper limit of normal for the LVEDI in our laboratory is $3 \mathrm{~cm} / \mathrm{m}^{2}$.) Three patients had a normal LVEDI and an EF $<0.45$. Twenty-five patients had a normal LVEDI and an EF $>0.45$.

The relation between the LVEDI and the ventriculographic left ventricular end diastolic volume index (LVEDVI) is shown in Fig. 3. Of the 15 patients with an LVEDI of $>3 \mathrm{~cm} / \mathrm{m}^{2}, 13$ had a raised LVEDVI ( $>95 \mathrm{ml} / \mathrm{m}^{2}$; the upper limit of normal for our laboratory is $95 \mathrm{ml} / \mathrm{m}^{2}$ ). Two patients had an increased LVEDVI and a normal LVEDI. Twenty-six patients had a normal LVEDI and a normal LVEDVI.

Fig. 4 illustrates the relation between the ventriculographic ejection fraction and the echocardio- 


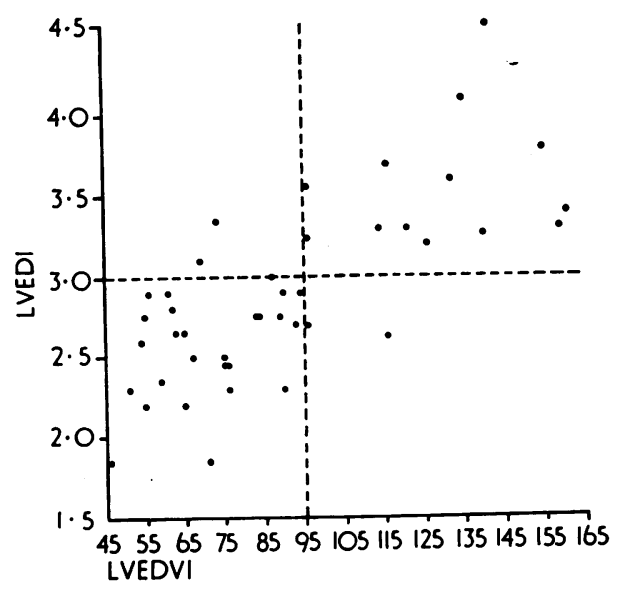

Fig. 3 The relation between the echocardiographic left ventricular end-diastolic dimension index (LVEDI) in $\mathrm{cm} / \mathrm{m}^{2}$ and the ventriculographic end-diastolic volume index (LVEDVI) in $\mathrm{ml} / \mathrm{m}^{2}$ is shown. The horizontal dotted line shows the upper limit of normal $\left(3 \mathrm{~cm} / \mathrm{m}^{2}\right)$ for the LVEDI. The vertical dotted line corresponds to the upper limit of normal for the LVEDVI $\left(95 \mathrm{ml} / \mathrm{m}^{2}\right)$. The correlation coefficient for this relation is 0.74 . graphic \%FSLV. The \%FSLV was reduced to $<28$ per cent (the lower limit of normal for our laboratory is $28 \%$ ) in 20 patients. In 14 of these patients the EF was $\leqslant 0.45$ and in 6 the EF was $>0.45$. The $\%$ FSLV was normal $(>28 \%)$ in 23 patients. In 2 of these the EF was $<0.45 \%$.

Abnormalities of left ventricular wall motion were frequently observed. Fourteen patients had diminished (i.e. $<0.4 \mathrm{~cm}$ ), absent, or paradoxical motion of the interventricular septum. (The lower limit of normal for displacement of the septum in our laboratory is $0.4 \mathrm{~cm}$.) Thirteen of these patients had significant stenosis of the left anterior descending coronary artery (LAD). The fourteenth patient did not have coronary arteriography, but had a welldocumented anteroseptal myocardial infarction in the past. On the other hand, 20 patients with significant stenosis of the LAD had septal motion which was within normal limits. Eleven patients had reduced motion $(<0.9 \mathrm{~cm})$ of the posterior left ventricular endocardial echo. (The lower limit of normal for our laboratory is $0.9 \mathrm{~cm}$.) Six of these subjects had right coronary artery disease, 2 had disease of the circumflex coronary artery, 1 had isolated disease of the $\mathrm{LAD}$, and 2 patients did not have coronary arteriography.

Examples of abnormal wall motion are illustrated in Fig. 5 and 6. Fig. 5 shows the left ventricular echocardiogram of a patient (Case 20) with normal

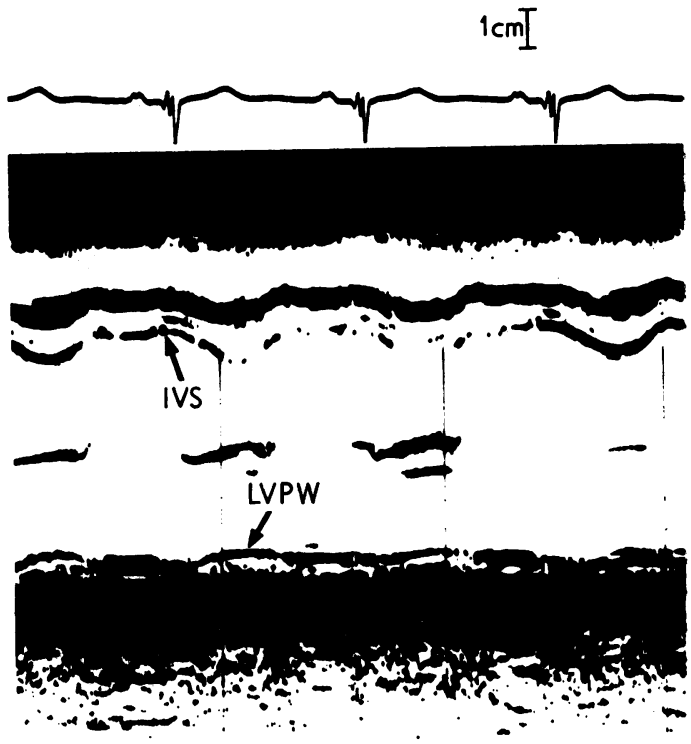

Fig. 5 The left ventricular echocardiogram of Case 20 shows normal septal motion and much reduced motion of the left ventricular posterior wall ( $L V P W)$. IVS = interventricular septum. 

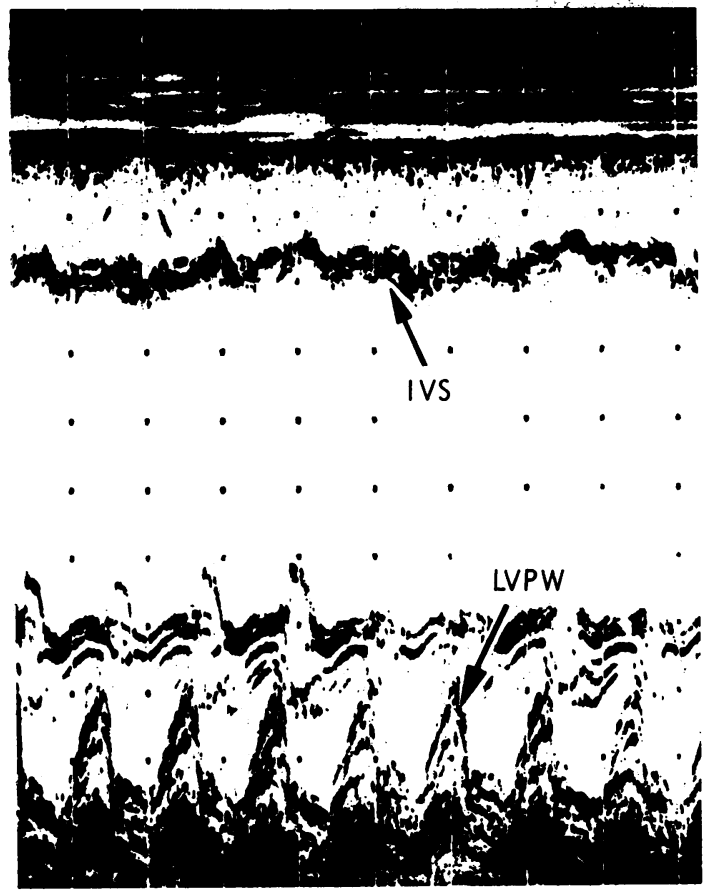

Fig. 6 The ultrasound recording of Case 21 is shown. The left ventricle is conspicuously dilated. There is excessive motion of the left ventricular posterior wall (LVPW) to compensate for absent systolic motion of the interventricular septum (IVS), which is a thin structure.

septal motion and pronounced reduction of posterior wall motion. The left ventricular echocardiogram of Case 21 is illustrated in Fig. 6. His ventriculographic ejection fraction was $0 \cdot 17$. The LVED was very enlarged $(7 \cdot 3 \mathrm{~cm})$, with absent septal motion and there was a compensatory increase of motion of the posterior wall.

\section{Discussion}

Aortocoronary saphenous vein graft surgery is useful in the treatment of patients with angina pectoris who are refractory to medical therapy. Symptomatic relief of angina occurs in the majority of patients who have this operation (Spencer, 1970). Though the mortality for bypass surgery is relatively low in patients with good left ventricular function, the risk of surgery is considerably more for those with impaired left ventricular performance (Cohn et al., 1974). Thus, the assessment of left ventricular function in these patients is of considerable prognostic importance. The left ventricular end-diastolic pressure, cardiac index, stroke work index, and the left ventricular ejection fraction have all been used as indices of left ventricular performance at cardiac catheterisation. Recent reports have indicated that the ejection fraction is the most useful index of left ventricular function in patients with coronary arterial disease (Cohn et al., 1974). Patients with an ejection fraction of 0.45 or more have been considered suitable candidates for myocardial revascularisation (Committee on Coronary Artery Surgery, 1972).

In this study we used single plane ventriculograms to determine ventricular volumes and ejection fraction. We realise the limitations of this method in assessing the above values in those patients who have left ventricular asynergy. Ideally, the biplane method should be used since the single plane method tends to underestimate the ejection fraction.

The role of echocardiography in the assessment of patients with valvular and congenital heart disease has been firmly established (Zaky et al., 1968; Feigenbaum, 1972; Chung et al., 1973; Popp et al., 1974). Recent studies have indicated the value of ultrasound in estimating the mean velocity of circumferential fibre shortening and fractional shortening of the left ventricular dimensions (McDonald et al., 1972; McDonald, and Hobson, 1974; Quinones et al., 1974). Echocardiography has been used to detect abnormalities of the left ventricular wall in patients with coronary arterial disease (Jacobs et al., 1973; Corya et al., 1974a). Klein et al. (1967) showed that ventricular dilatation occurred when an area of akinesis (or ventricular aneurysm) exceeded 20 to 25 per cent of ventricular surface area. Their observations were substantiated by Kitamura and co-workers (1973) who noted an increase of the end-diastolic volume and reduction of the ejection fraction when the area of the noncontractile area exceeded 20 to 30 per cent of the end-diastolic surface area of the left ventricle. Our study shows that the majority (15 of 17) of patients with an increased left ventricular end-diastolic dimension (LVED) measured by echocardiography had a critical reduction of ventriculographically determined ejection fraction ( 0.45 or less).

When the LVED was corrected for body surface area, all 15 patients with an increased LVEDI had an ejection fraction of 0.45 or less. Three patients with ejection fractions of 0.45 or less had left ventricular dimensions which were within normal limits. Thus an increased LVEDI was invariably associated with a critical reduction of EF, whereas a normal LVEDI did not necessarily imply an EF $>0.45$.

Our observations show that despite the presence of areas of asynergy an increase of the echocardiographic left ventricular end-diastolic dimension 
index is usually associated with an increase of the ventriculographic end-diastolic volume index. Six patients with reduced \%FSLV had ejection fractions of $>0.45$, and 2 patients with normal $\%$ FSLV had ejection fractions of $<0.45$. Thus $\%$ FSLV is a less useful indicator of poor left ventricular function than the LVEDI, in patients with coronary arterial disease. This is probably because, in the presence of asynergy, \%FSLV only reflects the performance of the visualised segment and not that of the entire myocardium.

Abnormalities of the left ventricular wall motion were commonly observed. Reduced motion of the interventricular septum was invariably associated with significant stenosis of the left anterior descending artery (LAD). However, several patients with significant LAD disease had normal septal motion. A compensatory increase in motion of the left ventricular posterior wall $(>1.5 \mathrm{~cm}$; the upper limit of normal for our laboratory is $1.5 \mathrm{~cm}$ ) was observed in 6 patients who had absent septal motion.

In summary, our investigation indicates that enlargement of the echocardiographic left ventricular end-diastolic dimension index is usually associated with a critical reduction of the ventriculographic ejection fraction. Since patients with compromised ventricular function are not ideal candidates for aortocoronary saphenous vein graft surgery, the ability to predict a poor ejection fraction by a noninvasive method is of considerable prognostic import. We realise the limitations of a single plane echocardiogram in evaluating overall left ventricular function in coronary arterial disease. Our data indicate, however, that useful information can be gleaned from an ultrasound recording in spite of these limitations.

\section{References}

Chung, K. J., Nanda, N. C., Manning, J. A., and Gramiak, R. (1973). Echocardiographic findings in tetralogy of Fallot. American fournal of Cardiology, 31, 126.

Cohn, P. F., Gorlin, R., Cohn, L. H., and Collins, J. J. (1974). Left ventricular ejection fraction as a prognostic guide in surgical treatment of coronary and valvular heart disease. American fournal of Cardiology, 34, 136-141.
Committee on Coronary Artery Surgery (1972). Optimal resources for coronary artery surgery. Circulation, 46, A-325-A-339.

Corya, B. C., Feigenbaum, H., Rasmussen, S., and Black, M. J. (1974a). Anterior left ventricular wall echoes in coronary artery disease. American fournal of Cardiology, 34, 652-657.

Corya, B. C., Feigenbaum, H., Rasmussen, S., and Black, M. J. (1974b). Echocardiographic features of congestive cardiomyopathy compared with normal subjects and patients with coronary artery disease. Circulation, 49, 1153-1159.

Feigenbaum, H. (1972). Echocardiography. Lea and Febiger, Philadelphia.

Jacobs, J. J., Feigenbaum, H., Corya, B. C., and Phillips, J. F. (1973). Detection of left ventricular asynergy by echocardiography. Circulation, 48, 263-271.

Kitamura, S., Kay, J. H., Krohn, B. G., Magidson, O., and Dunne, E. F. (1973). Geometric and functional abnormalities of the left ventricle with a chronic localised noncontractile area. American fournal of Cardiology, 31, 701707.

Klein, M. D., Herman, M. V., and Gorlin, R. (1967). A hemodynamic study of left ventricular aneurysm. Circulation, 35, 614-630.

McDonald, I. G., Feigenbaum, H., and Chang, S. (1972). Analysis of left ventricular wall motion by reflected ultrasound. Circulation, 46, 14-25.

McDonald, I. G., and Hobson, E. R. (1974). A comparison of the relative value of non-invasive techniques-echocardiography, systolic time intervals, and apex cardiography in the diagnosis of primary myocardial disease. American Heart Fournal, 88, 454-462.

Popp, R. L., Brown, O. R., Silverman, J. F., and Harrison, D. C. (1974). Echocardiographic abnormalities in the mitral valve prolapse syndrome. Circulation, 49, 428-433.

Quinones, M. A., Gassch, W. H., and Alexander, J. K. (1974). Echocardiographic assessment of left ventricular function with special reference to normalised velocities. Circulation, 50, 42-51.

Sandler, H., and Dodge, H. T. (1968). The use of single plane angiocardiograms for the calculation of left ventricular volume in man. American Heart fournal, 75, 325-334.

Spencer, F. C. (1970). Venous bypass grafts for occlusive disease of the coronary arteries. American Heart fournal, 79, 568-571.

Zaky, A., Nasser, W. K., and Feigenbaum, H. (1968). A study of mitral valve action recorded by reflected ultrasound and its application in the diagnosis of mitral stenosis. Circulation, 37, 789-799.

Requests for reprints to Dr. P. A. N. Chandraratna, Cardiovascular Section, The University of Oklahoma, Health Sciences Center, P.O. Box 25901, Oklahoma City, Oklahoma 73190, U.S.A. 